\title{
Sexual Behavior Activity Tracks Rapid Changes in Brain Estrogen Concentrations
}

\author{
Mélanie Taziaux, ${ }^{\star}$ Matthieu Keller, ${ }^{\star}$ Julie Bakker, and Jacques Balthazart \\ Center for Cellular and Molecular Neurobiology, University of Liège, B-4000 Liège, Belgium
}

Estrogens are classically viewed as hormones that bind to intracellular receptors, which then act as transcription factors to modulate gene expression; however, they also affect many aspects of neuronal functioning by rapid nongenomic actions. Brain estrogen production can be regulated within minutes by changes in aromatase (estrogen synthase) activity as a result of calcium-dependent phosphorylations of the enzyme. To determine the effects of rapid changes in estrogen availability on male copulatory behavior, we mimicked in male mice the rapid upregulation and downregulation of brain estrogen concentration that should occur after inactivation or activation of aromatase activity. A single injection of different aromatase inhibitors [Vorozole, 1,4,6-androstatrien-3,17-dione (ATD), or its metabolite 17-0HATD (1,4,6-androstatrien-17 $\beta$-ol-3-one)] almost completely suppressed male sexual behavior (mounts and intromissions) expressed 10-20 min later by C57BL/6 mice but did not affect behavior in aromatase knock-out (ArKO) mice, activated by daily injections of estradiol benzoate, thereby confirming the specificity of the behavioral inhibition observed in wild-type mice. The rapid ATD-induced inhibition was reversed by the simultaneous injection of a large dose of estradiol. A single injection of estradiol to ArKO mice also activated male sexual behavior within $15 \mathrm{~min}$. Thus, rapid increases or decreases in brain estrogen concentrations are followed within minutes by corresponding changes in male sexual behavior. Sexual behavior can thus be used to monitor changes in local estrogen concentrations and analyze the mechanisms mediating the rapid decline in estrogen signaling that takes place after inhibition of estrogen synthesis.

Key words: aromatase; aromatase knock-out mice; male sexual behavior; estrogens; rapid effects of steroids; nongenomic effects

\section{Introduction}

Steroids regulate the transcription of hormone-sensitive genes, but estradiol-17 $\beta\left(\mathrm{E}_{2}\right)$ also exerts rapid nongenomic effects at the neuronal membrane level and, for example, modulates brain electrical activity, ion channel function, or G-protein-coupled receptor activity (McEwen and Alves, 1999; Kelly and Ronnekleiv, 2002). The impact of these rapid cellular effects of $E_{2}$ on the functioning of the entire organism is, however, poorly documented.

Estrogen synthase (aromatase) is expressed in the brain (Naftolin et al., 1975) partly at the presynaptic level (Schlinger and Callard, 1989; Naftolin et al., 1996; Peterson et al., 2005). Changes in brain aromatase activity (AA) result primarily from slow steroid-dependent changes in enzyme transcription (Balthazart and Ball, 1998), but calcium-dependent phosphoryla-

\footnotetext{
Received Dec. 2, 2006; revised May 10, 2007; accepted May 14, 2007.

This work was supported by National Institutes of Health Grants R01 HD044897, R01 MH50388, Fonds National de la Recherche Scientifique (Belgium) Grant FNRS1.5.082.04, and Fonds National de la Recherche Fondamentale Collective (Belgium) Grant FRFC2.4562.05. J. Baker is a research associate at the Fonds National de la Recherche Scientifique, Belgium. We thank Quentin Douhard for dedicated technical help.

${ }^{*}$ M.T. and M.K. contributed equally to this work.

Correspondence should be addressed to Dr. Jacques Balthazart, Center for Cellular and Molecular Neurobiology, Research Group in Behavioral Neuroendocrinology, University of Liège, 1 Avenue de l'Hôpital (Bat. B36), B-4000 Liège 1, Belgium. E-mail: jbalthazart@ulg.ac.be.

M. Keller's present address: Laboratoire de Physiologie de la Reproduction et des Comportements, Unité Mixte de Recherche 6175, Institut National de la Recherche Agronomique/Centre National de la Recherche Scientifique/ University of Tours, 37380 Nouzilly, France.

DOI:10.1523/JNEUROSCI.1797-07.2007

Copyright $\odot 2007$ Society for Neuroscience $\quad$ 0270-6474/07/276563-10\$15.00/0
}

tions also inhibit AA within minutes in hypothalamic homogenates (Balthazart et al., 2001, 2003). Activation of glutamatergic receptors and changes in calcium concentrations also suppress AA in hypothalamic explants (Balthazart et al., 2003, 2006), and significant decreases in preoptic AA are observed 1-5 min after copulation in male quail (Cornil et al., 2005), probably as a consequence of glutamate release (Dominguez et al., 2006). There is also a tonic glutamatergic electrical activity in the preoptic area (Cornil et al., 2004), suggesting that, in vivo, aromatase is constantly upregulated and downregulated by changes in glutamatergic inputs and thus never displays its maximal enzymatic velocity. Together, these data indicate that brain estrogen production changes more rapidly than previously thought (Balthazart and Ball, 2006; Cornil et al., 2006c).

Rapid changes in brain estrogen concentrations at the presynaptic level are currently impossible to measure because of their transient and anatomically discrete nature combined with limits in assay sensitivity. Therefore, these changes can only be assessed indirectly by analyzing their functional consequences. Male sexual behavior offers excellent opportunities to investigate the relative contribution of genomic and nongenomic effects of estrogen. This behavior is activated in many species by estrogens derived from brain aromatization of testosterone that act primarily by activating transcriptional activity of nuclear estrogen receptors (Meisel and Sachs, 1994; Hull et al., 2002). However, recent studies suggest that estrogen also affects sexual behavior more rapidly, but these experiments did not test the specific role of 
brain aromatase in these behavioral effects (Cross and Roselli, 1999; Cornil et al., 2006a,b).

Here, we investigated whether increases or decreases in estrogen concentrations (after injection of $\mathrm{E}_{2}$ and/or of aromatase inhibitors) rapidly modulate the expression of sexual behavior in male mice. We used the aromatase knock-out mouse (ArKO) as an animal model to determine the behavioral specificity of the effects of the aromatase inhibitors used to decrease estrogen availability. Because male ArKO mice appear to be more sensitive to estrogens (Agarwal et al., 2000; Wesson et al., 2006), they also make an ideal model to test rapid stimulatory effects of estrogens on male sexual behavior. Results of these studies indicate that sexual behavior can be used to monitor local estrogen brain concentrations and analyze mechanisms mediating the rapid decline in estrogen signaling that occurs after inhibition of estrogen synthesis.

\section{Materials and Methods \\ Subjects and general procedure}

Gonadally intact male ArKO and wild-type (WT) mice from the C57BL/6J strain were used in these experiments. ArKO mice were generated by targeted disruption of exons 1 and 2 of the Cyp 19 gene (Honda et al., 1998). Heterozygous (HET) males and females of the C57BL/6J strain were bred to generate WT, HET, and homozygous-null (ArKO) offspring, which was genotyped by PCR analysis of tail DNA (Bakker et al., 2002a). It has been demonstrated previously that the expression of male sexual behavior is estrogen dependent in this strain of mice: these behaviors are never expressed in males in which expression of the aromatase gene has been blocked (ArKO), and the behavior is essentially restored in ArKO males after treatment with exogenous $\mathrm{E}_{2}$ (Honda et al., 1998; Bakker et al., 2004). A contribution of androgens to the activation of some aspects of male sexual behavior (e.g., ejaculation) is, however, also detectable (Bakker et al., 2004).

All experimental mice were housed alone under a reversed light/dark (12 h LD) cycle. Food and water were always available ad libitum. All experiments were conducted in accordance with the guidelines set forth by the National Institutes of Health Guiding Principles for the Care and Use of Research Animals and were approved by the Ethical Committee for Animal Use of the University of Liège.

Stimulus WT females were derived from the same breeding colony. They were ovariectomized in adulthood and implanted subcutaneously with a SILASTIC capsule (inner diameter, $1.57 \mathrm{~mm}$; outer diameter, 2.41 $\mathrm{mm}$; length, $5 \mathrm{~mm}$ ) containing crystalline estradiol diluted 1:1 with cholesterol. Three hours before testing, stimulus females were given a subcutaneous injection with $500 \mu \mathrm{g}$ of progesterone. This treatment induces high levels of sexual receptivity in female mice (Bakker et al., 2002b). Behavioral tests were conducted between 10:00 A.M. and 4:00 P.M. during the dark phase of the LD cycle.

All compounds were dissolved in propylene glycol:saline (4:1) and delivered by subcutaneous injection in the neck of the subject. These compounds included the following: the nonsteroidal aromatase inhibitor Vorozole [VOR; R83842 (6-[(4-chlorophenyl)(1 H-1,2,4-triazol-1yl)methyl]-1-methyl-1 H-benzotriazole] (De Coster et al., 1990), generously provided by Dr. R. DeCoster (Janssen Research Foundation, Beerse, Belgium); the steroidal aromatase inhibitor 1,4,6-androstatrien3,17-dione (ATD; Steraloids, Wilton, NH) and one of its metabolites, 1,4,6-androstatrien-17 $\beta$-ol-3-one (17-OH-ATD; Steraloids) (Ellinwood et al., 1984); estradiol benzoate (EB) and $17 \beta$-estradiol ( $\mathrm{E}_{2}$; SigmaAldrich, Bornem, Belgium).

Three independent groups of WT (group A, $n=12$; group B, $n=10$; group $\mathrm{C}, n=21$ ) and two groups of $\mathrm{ArKO}$ (group D, $n=12$; group E, $n=$ 12) male mice were used in a total of 17 independent experiments (Expts.) described here (see Results). Most mice were thus used repeatedly in different experiments (group A: Expts. 1, 2, 7-11; group B: Expt. 3; group C: Expts. 4, 12, 13; group D: Expts. 5, 6, 14, 15, 17; group E: Expt. 16) and were always used as their own control as explained in more detail below. There was always at least 1 week between different experiments so that the behavior of subjects could return to baseline.

\section{Behavioral assessment}

In all experimental procedures, a trial refers to a set of two or three behavioral tests (depending on the experiment) during which each mouse was tested in the control and experimental condition(s). Each mouse was used as its own control and received an injection on one day either with (one of) the tested compound(s) or its vehicle and on a second (and third) day with the other compound(s). Two successive injections within a trial were separated by at least $3 \mathrm{~d}$ for aromatase inhibitors and by at least 1 or 2 weeks for estradiol injections to prevent long-term effects of these treatments.

Male sexual behavior. Before any experimental test, all subjects were given three $30 \mathrm{~min}$ pretests of sexual behavior during which they could interact freely with a sexually receptive female, and their behavior was quantified during the last (WT) or last two (ArKO) tests. Based on the results of these pretests, subjects were ranked in decreasing order of performance, and if two (three) experimental conditions had to be tested during a trial, this series was split starting at the top into blocks of two (three) subjects. Within each block, subjects were then randomly assigned to the two (three) experimental groups, and statistical analyses were performed to confirm that these groups were behaviorally matched and did not differ significantly. The mice from all groups were then successively tested in a counterbalanced sequence in the two or three experimental conditions of the trial.

All sexual behavior tests were conducted in a Plexiglas aquarium (35 $\mathrm{cm}$ long $\times 25 \mathrm{~cm}$ high $\times 19 \mathrm{~cm}$ wide), the floor of which was covered with fresh sawdust. Immediately after the drug injection, the experimental subject was placed alone in the cage and allowed to adapt for $10 \mathrm{~min}$. A stimulus female was then placed in the test arena, and the latency to the first mount (ML), intromission (IL), and ejaculation (EL), as well as the number of mounts, intromissions, and ano-genital investigations (AGIs) were recorded during three successive periods of $10 \mathrm{~min}$. The test lasted until ejaculation occurred or for $30 \mathrm{~min}$ if no ejaculation was achieved. If a male did not display a given behavior within the $30 \mathrm{~min}$ test, it was assigned a latency of $1800 \mathrm{~s}$ for statistical analysis. The numbers of behaviors observed were divided by the actual duration of the test (first 10 min or total $30 \mathrm{~min}$ or ejaculation latency) to provide frequencies per minute (or rates) of mounts (MF), intromissions (IF), and AGIs (AGIF) that would not be adversely affected in subjects who achieved ejaculation during the test. These behavioral frequencies per minute were used in all analyses presented here.

Open-field test. Mice were tested for general locomotor activity in an open field (clean Plexiglas cage; 51 long $\times 18$ high $\times 30 \mathrm{~cm}$ wide). The cage was divided into nine rectangles. Ten minutes after injection, the subject was placed in a corner of the cage. The number of line crossings (from one rectangle to another) was recorded during $10 \mathrm{~min}$. We considered a line crossed when all four legs were over the line.

Odor preference in a $Y$-maze. Tests measuring olfactory investigation of volatile body odors and of odor preference were also conducted to determine whether experimental manipulations affecting male copulatory behavior would also affect aspects of sexual motivation such as odor preference. It is firmly established that olfactory cues play a key role in the control of mouse sexual behavior (Keller et al., 2006), and alterations of these sensory inputs could have indirectly caused the deficits in sexual behavior observed after injections of aromatase inhibitors. The time spent investigating volatile odors from a male or female conspecific as well as the preferential orientation of these investigations toward odors from estrous females as opposed to males are severely disrupted in ArKO as well as in estrogen receptor- $\alpha$ knock-out mice (Wersinger and Rissman, 2000; Bakker et al., 2002a), indicating a role of estrogens in the control of these responses, although it is still not clear yet whether this behavior disruption reflects organizational or activational effects of the steroid. The olfactory preference test therefore cannot be used to assess the endocrine specificity of the aromatase inhibitors effects but provides a fine measure of the behavioral specificity (performance vs motivation in sexual behavior) of the rapid effects of estrogens. This test was conducted in an enclosed Plexiglas Y-maze (for description, see Bakker et al., 2002a). The goal boxes contained an estrous female (same endocrine condition as the stimulus females in the sexual behavior tests) on one side and a sexually active male on the other side (sides were changed between 
tests and were always assigned randomly). Stimulus animals were anesthetized and placed behind black doors to prevent the subjects from seeing and hearing the stimulus animals. Subjects were given injections of the test compound and placed 10 min later in the maze. We then recorded during $5 \mathrm{~min}$ the time that the subject spent sniffing the male and female volatile odor stimuli. The Y-maze was always cleaned with $70 \%$ ethanol between tests.

\section{Statistical analysis}

Sexual behavior was recorded for a total of $30 \mathrm{~min}$ divided in three $10 \mathrm{~min}$ periods. Statistical analyses were performed both on the results obtained during the entire test and during the first $10 \mathrm{~min}$. Because the distributions of sexual behavior frequencies and latencies did not follow a normal distribution (Shapiro-Wilk test, $p>0.5$ ), they were analyzed by nonparametric tests for repeated design (Wilcoxon signed-ranks tests or Friedman rank ANOVAs depending on the number of conditions in the trial). When appropriate, Friedman rank ANOVAs were followed by post hoc comparisons between groups (Siegel and Castellan, 1988). The Fisher's exact probability test was used to compare the proportion of active versus inactive subjects. Parametric ANOVAs were used for all other data that were normally distributed and were followed, when appropriate, by post hoc comparisons with the Tukey's honestly significant difference test. All data presented in the figures and tables are means \pm SEM. Differences were considered significant for $p<0.05$.

\section{Results}

\section{Inhibition of estrogen synthesis rapidly suppresses} sexual behavior

A single injection of a specific aromatase inhibitor [VOR (1 mg per subject; Expt. 1), or ATD (4 mg per subject; Expt. 2), or 17-OH-ATD (4 mg per subject; Expt. 3)] produced a rapid and pronounced inhibition of sexual behavior in WT mice measured during a $30 \mathrm{~min}$ period starting $10 \mathrm{~min}$ after the injection. Mount and intromission rates were markedly reduced in the aromatase inhibitors condition compared with the corresponding control condition both during the first 10 min of test (all $p<0.05$ ) (Fig. 1 ) and during the entire test (supplemental Table $1 \mathrm{~A}$, available at www.jneurosci.org as supplemental material).

Almost all aromatase inhibitor-treated males failed to mount the female during the first $10 \mathrm{~min}$ of test (11 of 12 for VOR or ATD and 8 of 10 for 17-OH-ATD), and only one (ATD) or none (VOR, 17-OH-ATD) of them showed some intromission behavior. In contrast, most of these subjects displayed these behaviors in the corresponding control condition (MF: 11 or 12 of 12 for VOR or ATD, respectively, and 7 of 10 for 17-OH-ATD; IF: 9 or 7 of 12 for VOR or ATD, respectively, and 7 of 10 for $17-\mathrm{OH}-$ ATD; $p<0.05$ in all cases by bilateral Fisher's exact probability test, except for MF after 17-OH-ATD in which $2 \mathrm{p}=0.064$ ). The latencies of first mount or intromission (when present) were also significantly longer in all aromatase inhibitor-treated males than in the corresponding control condition (supplemental Table 1B, available at www.jneurosci.org as supplemental material). In contrast, decreases in AGI were more modest, and a significant difference was observed only after ATD treatment $(p<0.01$ at 10 or 30 min of test) (Fig. 1 and supplemental Table 1A, available at www.jneurosci.org as supplemental material).

\section{Recovery from behavioral inhibition by ATD}

The behavioral inhibition induced by a single injection of an aromatase inhibitor was only transient. In Expt. 4, 11 male WT mice (half of the subjects of group C) were tested for sexual behavior $10 \mathrm{~min}$ and $24 \mathrm{~h}$ after a single injection of $1 \mathrm{mg}$ of ATD. This lower dose of aromatase inhibitor resulted like the higher dose, in a nearly complete inhibition of male sexual behavior (mean numbers of mounts and intromissions per minute during
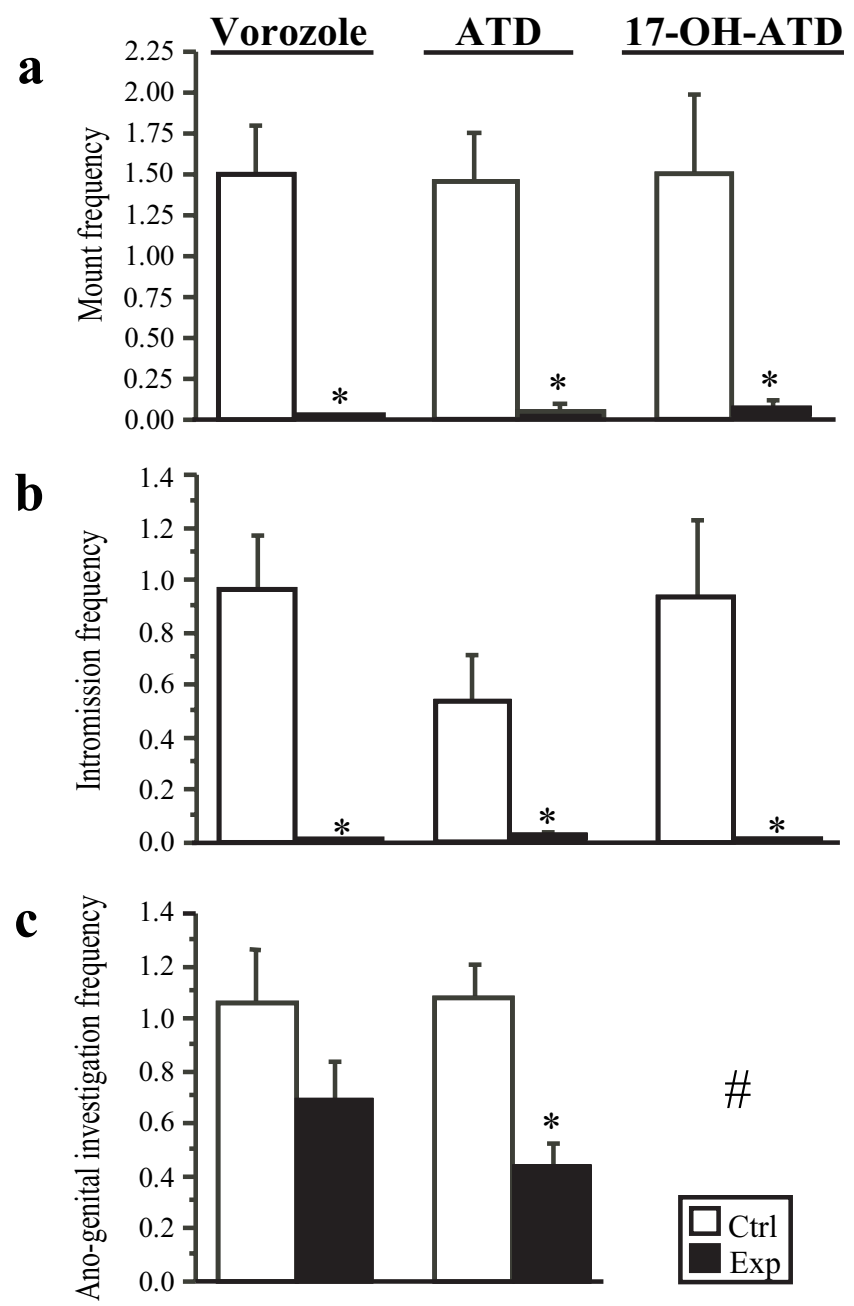

Figure 1. Effects of aromatase inhibitors on male sexual behavior during the first $10 \mathrm{~min}$ of a 30 min test starting 10 min after the injection. $\boldsymbol{a}-\boldsymbol{c}$, The mean frequencies ( \pm SEM) per minute of mounts $(\boldsymbol{a})$, intromissions $(\boldsymbol{b})$, and AGIs (c) of WT males that received a single injection of an aromatase inhibitor [Exp; $n=12$ for VOR (1 mg per subject) and ATD ( $4 \mathrm{mg}$ per subject); $n=10$ for 17-0H-ATD ( $4 \mathrm{mg}$ per subject)] or its vehicle (Ctrl) are shown. ${ }^{*} p<0.05$ compared with Ctrl. "Data not collected.

the first 10 min of tests were lower than 0.1 ; latencies were longer than $7 \mathrm{~min}$ ) (Fig. 2). When retested the next day, all of these males displayed frequencies and latencies of mounts and intromissions typical of normal untreated WT males (compare Fig. 2 with control data in Fig. 1), confirming the absence of a long-term effect of this treatment.

\section{Rapid inhibitory effects of aromatase inhibitors on sexual} behavior are specifically attributable to the blockade of AA To test whether the rapid behavioral effects of aromatase inhibitors on sexual behavior resulted specifically from the blockade of estrogen production, we assessed the effect of two aromatase inhibitors on sexual behavior of male ArKO mice. Previous work showed that suppression of estrogen synthesis by disruption of the Cyp19 gene encoding for aromatase results in severe deficits in many aspects of sexual behavior, including partner preference, sexual motivation, and performance (Honda et al., 1998; Bakker et al., 2002a,b, 2004; Matsumoto et al., 2003). However, these deficits are almost completely restored by adult treatment with estrogens (Bakker et al., 2004). If the rapid behavioral inhibitory 


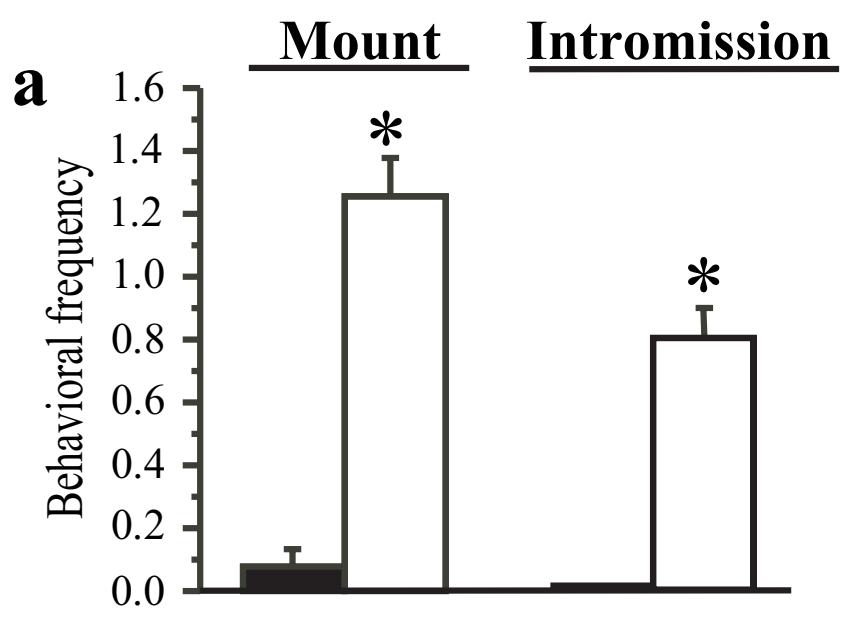

$\mathbf{a}$

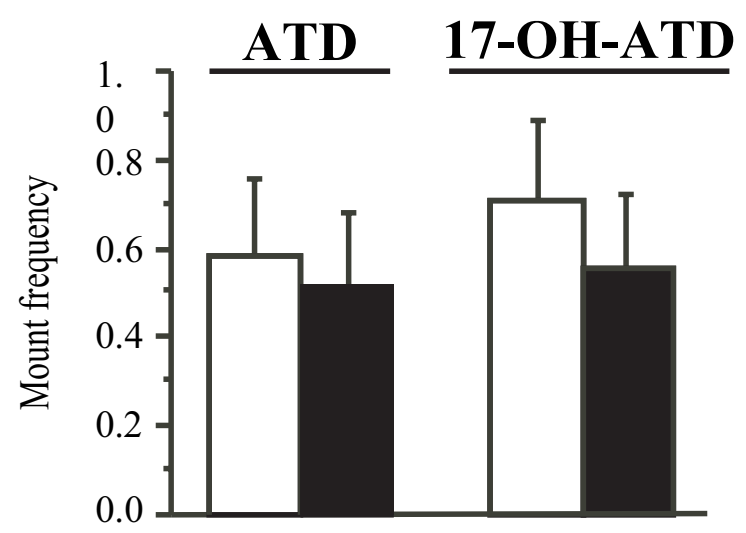

b

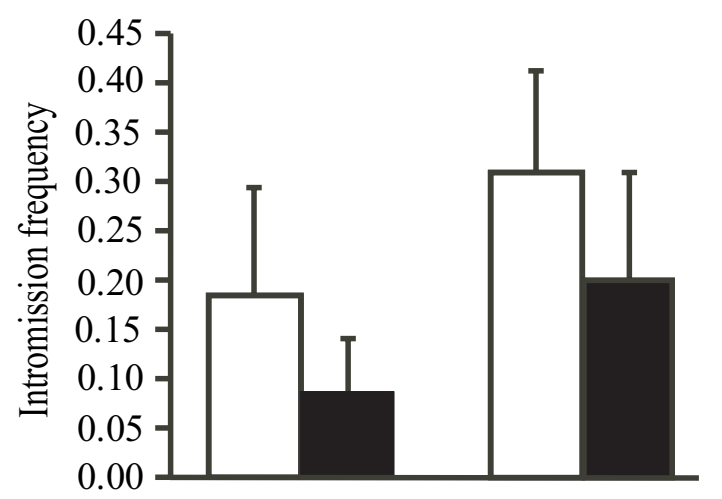

c

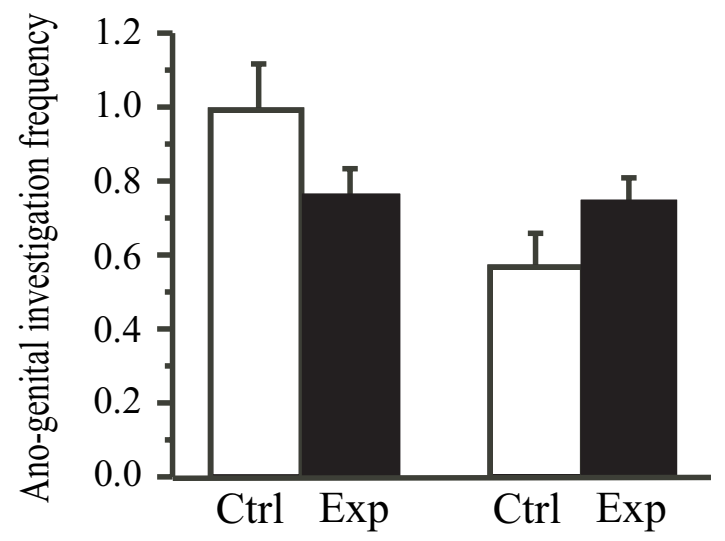

Figure 3. Effects of aromatase inhibitors on male sexual behavior of ArKO mice during the first $10 \mathrm{~min}$ of a $30 \mathrm{~min}$ test starting $10 \mathrm{~min}$ after the injection. $\boldsymbol{a}-\boldsymbol{c}$, The mean frequencies ( \pm SEM) per minute of mounts $(\boldsymbol{a})$, intromissions ( $\boldsymbol{b})$, and AGIs (c) of EB-primed ArKO males that were either given injections of $4 \mathrm{mg}$ of ATD per subject (Exp; $n=12 ;$ ) or $4 \mathrm{mg}$ of 17-OH-ATD per subject (Exp; $n=12$ ) or their vehicle (Ctrl; $n=12$ ) are shown. ${ }^{*} p<0.05$ compared with Ctrl.

(compare Figs. 1, 3, 5 and corresponding data for the entire 30 min of test in supplemental Tables 1-3, available at www.jneurosci.org as supplemental material). There was therefore enough room for an inhibition of the EB-induced copulatory behavior of ArKO mice by aromatase inhibitors, and the finding that this inhibition did not take place in ArKO mice strongly supports the notion that the inhibition of behavior results from a blockade of the aromatase enzyme rather than any other nonspecific mechanism.

ArKO males that received injections of ATD also showed less AGI than in the control condition $(p<0.05)$ (supplemental Table 2A, available at www.jneurosci.org as supplemental mateATD ranged between 0.5 and 0.6 , whereas the same treatment in WT males is associated with MF $<0.1$ and very often equal to 0 
rial), but this decrease had a small amplitude and was not present during the first 10 min of test (Fig. 3).

\section{Behavioral specificity}

To further assess the specificity of the rapid effects of aromatase inhibitors on sexual behavior, male WT mice were tested for general locomotor activity in an open field $10 \mathrm{~min}$ after receiving injections on different days with two different doses of ATD [1 or $4 \mathrm{mg}$ per subject (Expts. 7, 8)]. As illustrated in Figure $4 a$, no difference in locomotor activity was detected in these males between the ATD and control conditions (repeated-measure ANOVA on the number of lines crossed; $1 \mathrm{mg}$ per subject: $F_{(1,11)}=1.14, p>0.3 ; 4$ mg per subject: $\left.F_{(1,11)}=2.27, p>0.1\right)$.

To test whether injections of the aromatase inhibitors also affected sexual motivation, male WT mice were tested for odor preferences in a Y-maze 10 min after receiving injections of ATD (1 mg per subject) or its vehicle (Expt. 9). Mice were first tested in the Y-maze with no stimulus subject placed in the goal boxes to adapt to the testing apparatus and to determine whether they would develop any side preferences. Then, they were tested for odor preferences when offered a choice between volatile body odors from an estrous female and those from an intact male. A weak, almost significant side preference $(p<0.1)$ was detected when subjects were tested without any stimulus animals placed in the goal boxes of the Y-maze. Therefore, the position of the stimulus animals was changed between tests. Males that received injections of ATD or its vehicle clearly preferred to investigate volatile odors from an estrous female over those from a sexually active male (Fig. 4b). A two-way ANOVA of the time spent investigating the different volatile olfactory cues with treatment as independent factor and odor stimuli (male vs female) as repeated factor identified a significant effect of the odor stimulus $\left(F_{(1,11)}=\right.$ 32.83; $p<0.001)$ but no significant effect of treatment $\left(F_{(1,11)}=\right.$ $1.46 ; p>0.2)$ and no treatment/stimulus interaction $\left(F_{(1,11)}=\right.$ 2.97; $p>0.1)$. Both in the ATD and control condition, males spent significantly more time investigating volatile odors from an estrous female than those from a male. A similar analysis performed on the number of entries into each arm of the Y-maze also showed a significant effect of the odor stimuli $\left(F_{(1,11)}=13.51\right.$; $p<0.01)$ but no effect of treatment and no interaction $(p>0.3)$. Again, subjects entered more frequently the arm containing the female than the arm containing the male stimulus, independently of whether they were treated with ATD or vehicle.

\section{Reversal by exogenous estradiol of the behavioral effects of} aromatase inhibitors

Next, we tested whether a single injection of $\mathrm{E}_{2}$ was able to reverse the inhibitory effects of aromatase inhibitors by quantifying sexual behavior in mice who had received an injection of ATD (4 mg per subject; Expt. 10) or 17-OH-ATD (4 mg per subject; Expt. 11) alone or combined with a simultaneous injection of $\mathrm{E}_{2}(20 \mu \mathrm{g}$ per subject) $10 \mathrm{~min}$ before testing.

The $\mathrm{E}_{2}$ injection only partially restored sexual behavior in ATD- or 17-OH-ATD-injected subjects compared with the control condition (Fig. 5). Friedman rank ANOVAs identified significant differences between the three test conditions (inhibitor alone or with $\mathrm{E}_{2}$ or vehicle) for almost all behavioral measures recorded during the first $10 \mathrm{~min}$ of behavior test for both aromatase inhibitors (ATD, all $p<0.05$ except IL; 17-OH-ATD, all $p<0.05$ except for AGIF and EL). Like in previous experiments, there was no significant effect of a 17-OH-ATD injection on AGI (Fig. 5).

Post hoc comparisons between groups confirmed the strong a Open field test

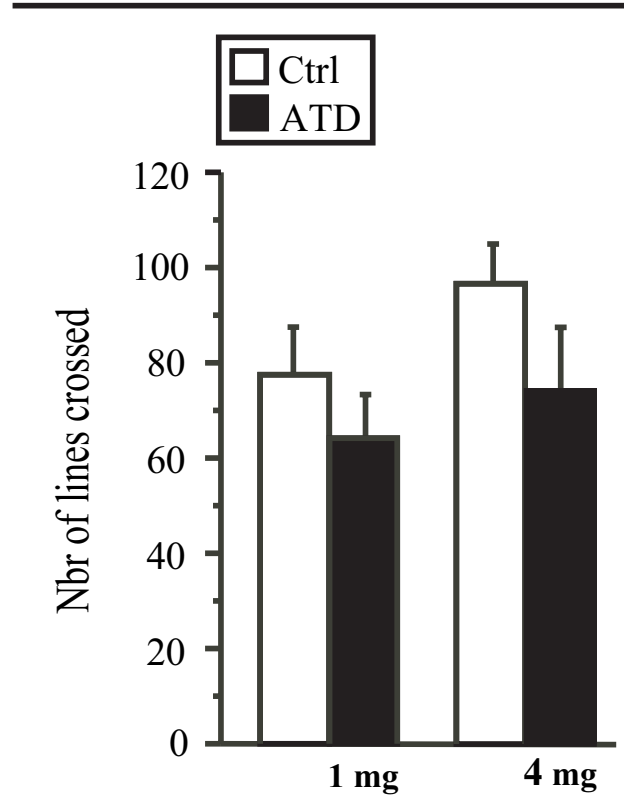

b Odor preference test

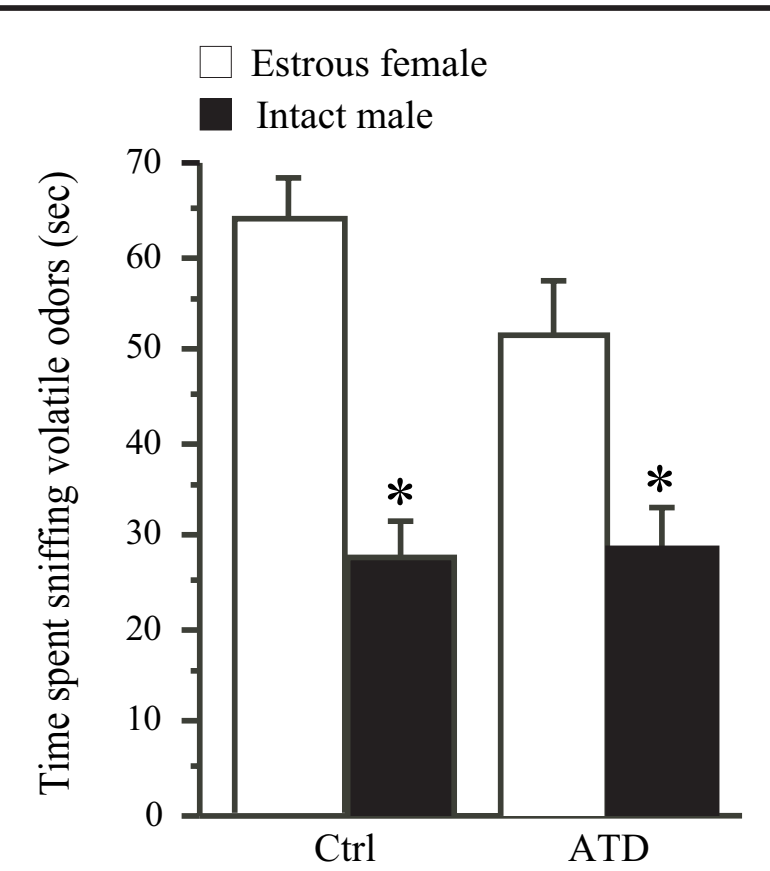

Figure 4. $a$, Mean number ( \pm SEM) of lines crossed in an open-field test by WT male mice between 10 and $20 \mathrm{~min}$ after injection of either 1 or $4 \mathrm{mg}$ of ATD per subject (Exp; $n=12$ ) or its vehicle (Ctrl; $n=12) \cdot \boldsymbol{b}$, Mean amount of time ( \pm SEM) that WT male mice that received an injection of either ATD ( $n=12,1 \mathrm{mg}$ per subject) or its vehicle (Ctrl; $n=12$ ) spent investigating volatile olfactory cues when given a choice between intact male odors and estrous female odors in a Y-maze during a 5 min test starting 10 min after injection. ${ }^{*} p<0.05$ compared with estrous female.

inhibition of sexual behavior by both aromatase inhibitors (ATD, $p<0.05$ for MF, IF, AGIF, and ML; 17-OH-ATD, $p<0.05$ for MF, IF, ML, and IL). Behavioral frequencies were systematically higher in mice that had received injections of the aromatase inhibitor and $\mathrm{E}_{2}$ than with the inhibitor alone, but they did not 

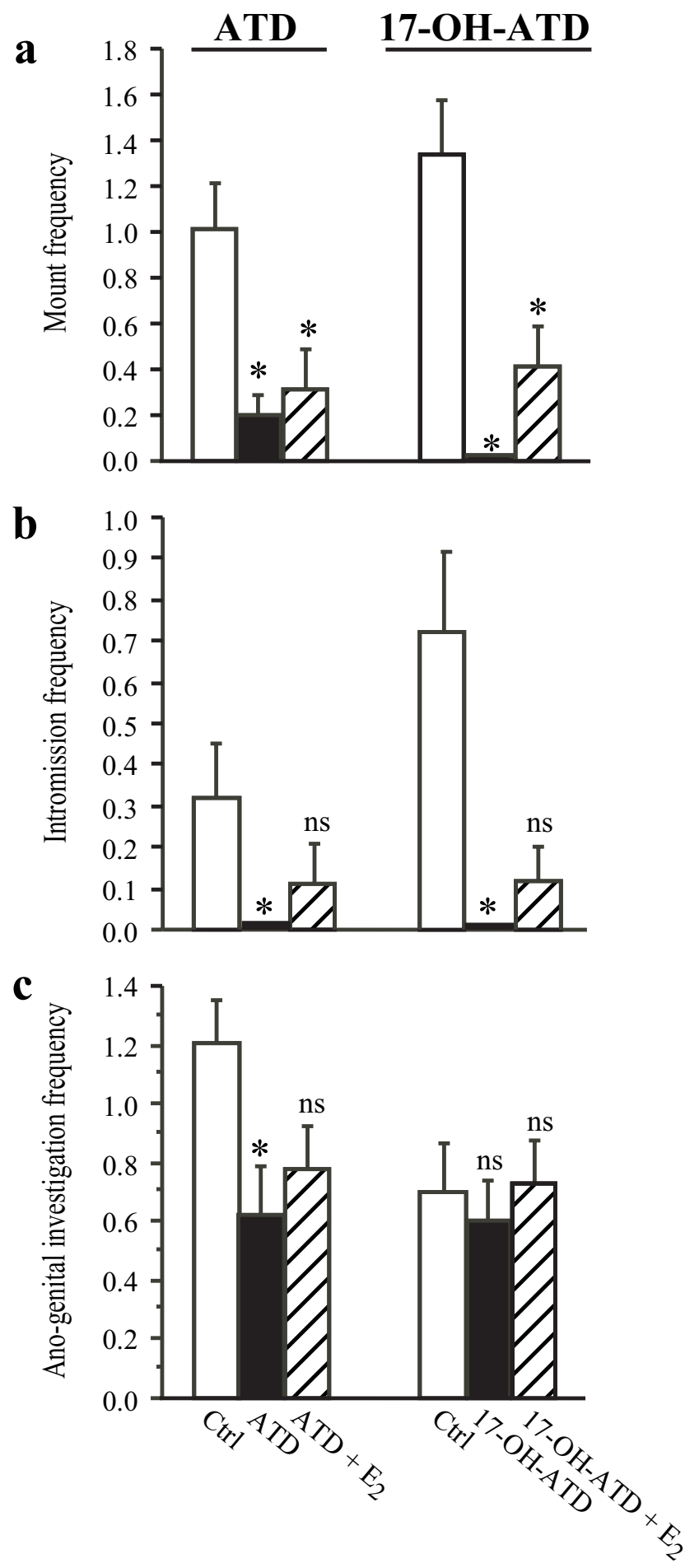

Figure 5. Reversibility of the behavioral effects of aromatase inhibitors by simultaneous estradiol injection during the first 10 min of a 30 min test starting 10 min after injection. $\boldsymbol{a}-\boldsymbol{c}$, The mean frequencies ( \pm SEM) per minute of mounts $(\boldsymbol{a})$, intromissions $(\boldsymbol{b})$, and AGIs $(\boldsymbol{c})$ of WT males ( $n=12$ for each condition) that were given an injection of either ATD or 17-0H-ATD alone (4 mg per subject) or combined with a simultaneous injection of $20 \mu \mathrm{g}$ of estradiol (ATD $+\mathrm{E}_{2}$ or $17-0 \mathrm{H}-\mathrm{ATD}+\mathrm{E}_{2}$ ) or vehicle $(\mathrm{Ctrl})$ are shown. ${ }^{*} p<0.05$ compared with $\mathrm{Ctrl}$. ns, Not significantly different from Ctrl.

reach the level seen in the control condition. Accordingly post hoc tests failed to identify significant differences between the aromatase inhibitor alone and the aromatase inhibitor plus $\mathrm{E}_{2}$ conditions, although for many behavioral measures, there was no longer a significant difference between the control and the inhibitor plus $\mathrm{E}_{2}$ condition (see the detail of these tests in Fig. 5 and supplemental Table 3B, available at www.jneurosci.org as supplemental material, for behavioral frequencies and latencies respectively).

Similar results were observed when data obtained during the entire test were analyzed (Friedman ANOVA: for ATD, all $p<$ 0.05; for 17-OH-ATD, all $p<0.05$ except AGIF and EL). Again, post hoc comparisons of the three groups two by two revealed a clear inhibitory effect of both aromatase inhibitors on sexual behavior (ATD, $p<0.05$ for MF, IF, AGIF, and ML; 17-OH-ATD, $p<0.05$ for MF, IF, ML, and IL), but no significant stimulatory effect of $E_{2}$ although behavioral frequencies in the inhibitor plus $\mathrm{E}_{2}$ condition were always numerically higher than in the inhibitor-alone condition (see supplemental Table 3A, available at www.jneurosci.org as supplemental material).

Based on these results, it was hypothesized that a higher dose of $E_{2}$ associated with a lower inhibition of behavior by ATD might result in a full restoration of behavior. In the subsequent experiment (Expt. 12), a dose of $1 \mathrm{mg}$ of ATD per subject was thus combined with an even larger dose of $\mathrm{E}_{2}$ (500 $\mu \mathrm{g}$ per subject) in an attempt to restore in the brain the high concentrations of estrogen that are presumably produced by local aromatization of testosterone [see Kretz et al. (2004) and Discussion]. This experiment, which for technical reasons only compared behavior during one test in two independent groups of 11 ATD-treated mice and 10 ATD plus $\mathrm{E}_{2}$-treated mice, demonstrated a significant increase of MF and ML in mice given injections of ATD plus $\mathrm{E}_{2}$ compared with mice given injections of ATD alone (see supplemental Table 4, available at www.jneurosci.org as supplemental material).

To further confirm this restoration of behavior by $E_{2}$ in subjects treated with an aromatase inhibitor, an additional experiment (Expt. 13) was performed in which the same dose of $E_{2}$ was tested (500 $\mu \mathrm{g}$ per subject), and repeated tests were performed 2 weeks apart to avoid potential interactions of the effects of the first $\mathrm{E}_{2}$ injection with results collected during the second test. We also decreased the ATD dose to $0.5 \mathrm{mg}$ per subject to optimize the probability of behavioral restoration. In the ATD-alone condition, mice displayed in this experiment behavioral frequencies (mount and intromission) that were clearly below those normally seen in untreated WT mice (compare Fig. 6 with Figs. 1, 5).

The concomitant injection of $\mathrm{E}_{2}$ more or less doubled these behavioral frequencies that were found to be significantly increased both during the first 10 min of test and during the entire test (see detail of statistics in Fig. 6). Like in previous experiments, the frequencies on AGIs were not affected by these treatments.

Estradiol rapidly stimulates sexual behavior in ArKO males To assess whether $E_{2}$ could rapidly stimulate sexual behavior, a series of experiments were performed in male ArKO mice that were suspected, based on previous experiments (Agarwal et al., 2000; Wesson et al., 2006), to be more sensitive to estrogen because of their constitutive lack of exposure to this steroid. Because previous reports had demonstrated that, in female rats, nongenomic (membrane) actions of estrogen facilitate their genomic actions both in vitro (Vasudevan et al., 2001) and in vivo (Kow and Pfaff, 2004), sexually experienced ArKO males [they had been treated previously with behaviorally active doses of EB, were tested for sexual behavior in the context of experiments described above (Expts. 5, 6), and then were left without EB for a period of 1 week] were treated daily for $9 \mathrm{~d}$ with a low dose of $\mathrm{EB}$ $(0.1 \mu \mathrm{g}$ per subject $)$ that is not sufficient to fully activate sexual 


\section{$\underline{\text { First } 10 \mathrm{~min}} \underline{\text { Entire Test }}$}

a

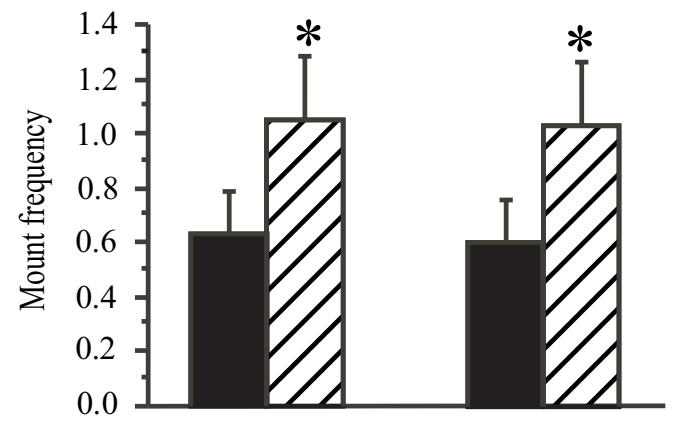

b

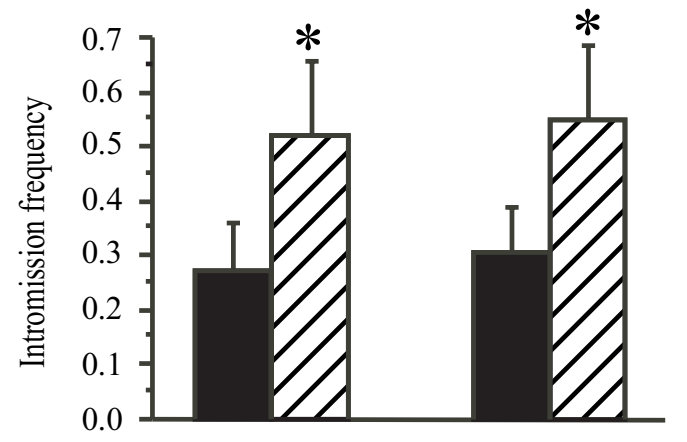

c

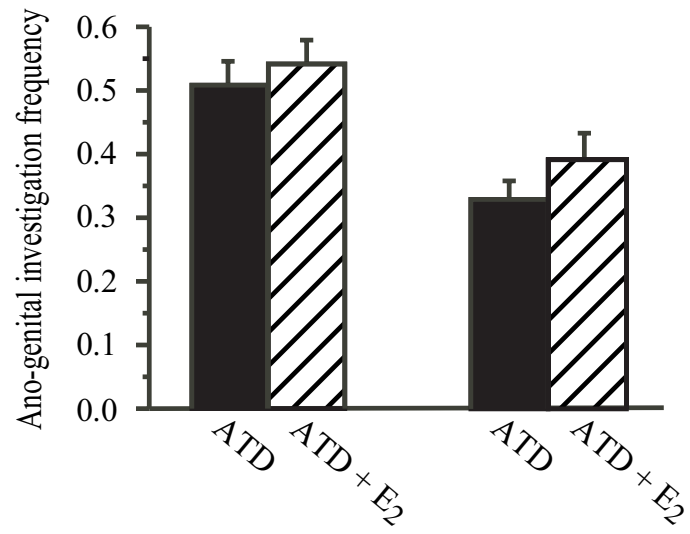

Figure 6. Effects of an acute estradiol injection ( $500 \mu \mathrm{g}$ per subject) on male sexual behavior of WT mice $(n=21)$ that had simultaneously received a single injection of ATD $(0.5 \mathrm{mg}$ per subject). $\boldsymbol{a}-\boldsymbol{c}$, The mean frequencies ( \pm SEM) per minute of mounts $(\boldsymbol{a})$, intromissions $(\boldsymbol{b})$, and AGIs (c) during the first 10 min of a 30 min test starting 10 min after injection (left column) and during the entire test (right column) are shown. ${ }^{*} p<0.05$ compared with ATD condition.

behavior and then received an injection of an acute dose of $\mathrm{E}_{2}(50$ $\mu \mathrm{g}$ per subject) and were tested $10 \mathrm{~min}$ later for sexual behavior (Expt. 14). The Wilcoxon signed rank test revealed that this combination of acute and chronic estrogen exposure significantly stimulated mounting behavior in male ArKO mice compared with tests performed after only the chronic exposure to a low dose of EB [frequencies from the first 10 min of test: MF: $t=3, n=8$, $p<0.05$ (see supplemental Table 5, available at www.jneurosci. org as supplemental material); ML: $t=0, n=8, p<0.05$ (data not shown)]. These increases in behavioral frequencies were not significant for data relative to the entire 30 min test (supplemental Table 5, available at www.jneurosci.org as supplemental material), but a significant decrease in mount latency was present in these data ( $t=0, n=8, p<0.05$; data not shown).

When tested exactly the same way (acute injection of $50 \mu \mathrm{g}$ of $\mathrm{E}_{2}$ per subject) but after a pretreatment with a higher dose of $\mathrm{EB}$

\section{First 10 min Entire Test}

$\mathbf{a}$

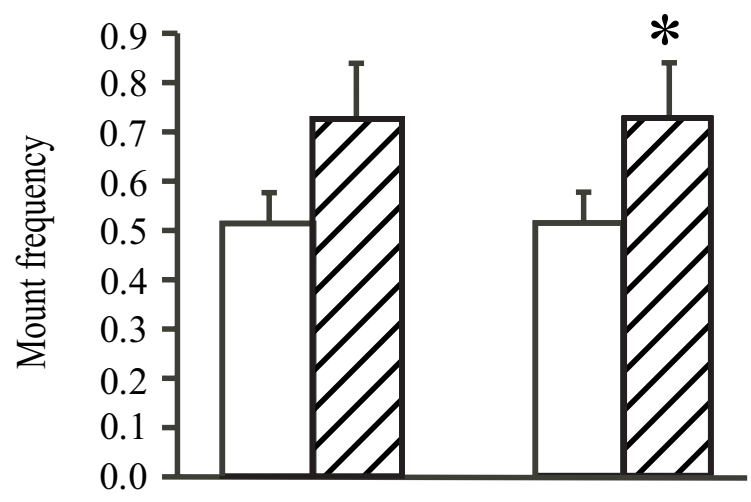

b
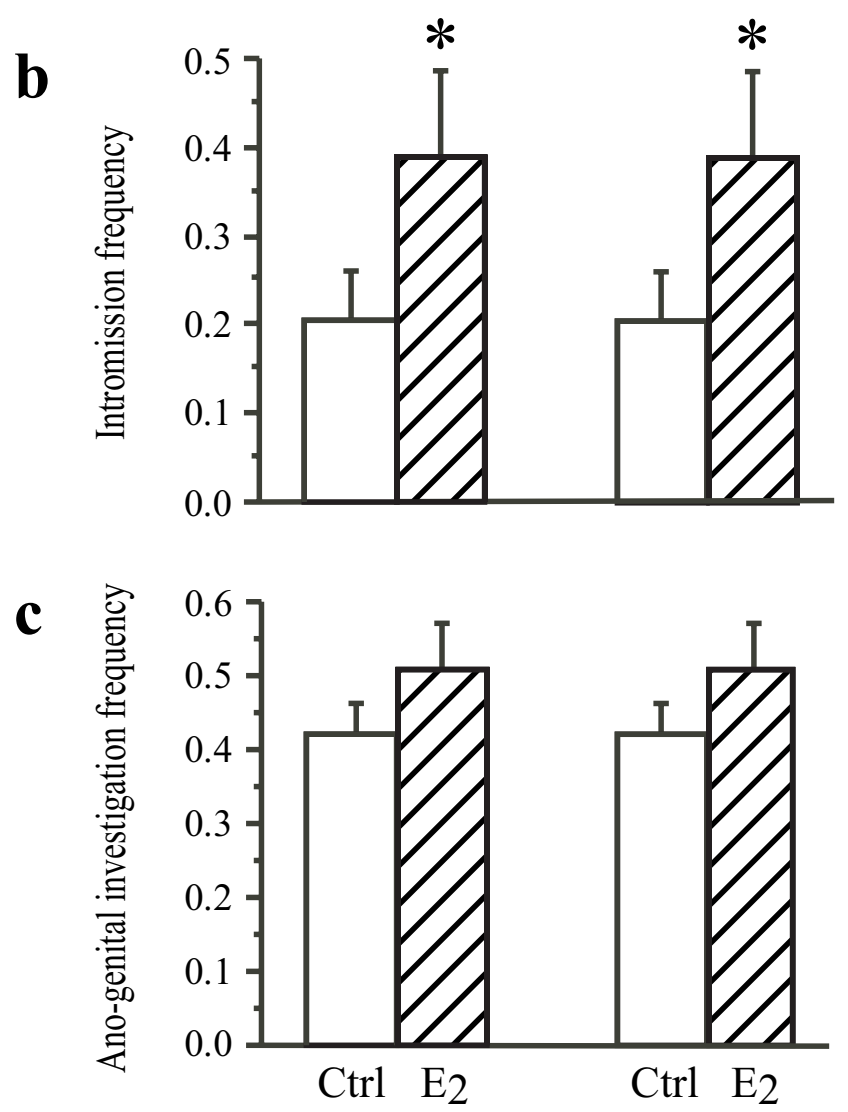

Figure 7. Effects of an acute estradiol injection on male sexual behavior of ArK0 mice during the first 10 min of a 30 min test starting 10 min after injection (left column) and during the entire test (right column). $\boldsymbol{a}-\boldsymbol{c}$, The mean frequencies ( \pm SEM) per minute of mounts $(\boldsymbol{a})$, intromissions $(\boldsymbol{b})$, and AGIs (c) of EB-primed ArKO males ( $0.5 \mu \mathrm{g}$ per subject per day for $9 \mathrm{~d})$ that received an injection of $50 \mu \mathrm{g}$ of estradiol $\left(\mathrm{E}_{2} ; n=12\right)$ or its vehicle $(\mathrm{Ctrl} ; n=12) .{ }^{*} p<0.05$ compared with Ctrl.

(0.5 $\mu$ g per subject; Expt. 15), frequencies of most sexual behaviors were significantly stimulated by the acute $\mathrm{E}_{2}$ injection both during the first $10 \mathrm{~min}$ test and during the entire test (Fig. 7) (First 10 min: MF, $t=12.5, n=11, p<0.07$; IF, $t=11, n=11$, $p<0.05$; Entire Test: MF, $t=6, n=10, p<0.05$; IF, $t=10.5, n=$ $11, p<0.05)$.

These rapid stimulatory effects of a single $\mathrm{E}_{2}$ injection $(20 \mu \mathrm{g}$ per subject) were not observed in sexually naive ArKO males that had never been tested for sexual behavior and that had not received injections of EB (Expt. 16; all $p>0.5$ for data during the 
first 10 min test or the entire test) nor in ArKO males that had gained mating experience during tests performed after treatment with EB ( $5 \mu \mathrm{g} / \mathrm{d}$ per subject) but had then been left for 1 month without exogenous EB and were tested $10 \mathrm{~min}$ after a single injection of $\mathrm{E}_{2}$ (20 and $50 \mu \mathrm{g}$ per subject; Expt. 17; all measures for the first $10 \mathrm{~min}$ of test and the entire test, Wilcoxon signed rank test, $p>0.1$; data not shown).

\section{Discussion}

Although it is now clear that estrogens have rapid (within minutes or even seconds) membrane-mediated effects on neuronal physiology (see Introduction), there is still little information demonstrating the impact of these cellular effects at the level of the entire organism. The present study clearly indicates that both increases and decreases in brain estrogen availability induce corresponding changes in overt behavior. Results in ArKO mice also fully establish that rapid behavioral inhibitions caused by aromatase inhibitors are specific to this enzymatic process and that rapid effects of estrogens supplement slower genomic effects to control male sexual behavior.

\section{Rapid effect of estradiol on male sexual behavior}

Previous experiments in rats (Cross and Roselli, 1999) and quail (Cornil et al., 2006a) showed that a single injection of $\mathrm{E}_{2}$ stimulates aspects of male sexual behavior. These effects were, however, observed after longer latencies than in the present study, they were limited to specific aspects of the behavioral repertoire, and they were not reproduced in all tests (Cornil et al., 2006a). ArKO mice that are presumably more sensitive to estrogen action (Agarwal et al., 2000; Wesson et al., 2006) displayed a very robust stimulation of most aspects of male sexual behavior within 15 min after a single peripheral injection of $E_{2}$ (tests started $10 \mathrm{~min}$ later, and most behavior latencies shorter than $5 \mathrm{~min}$ ).

This rapid behavioral effect of $\mathrm{E}_{2}$ was best observed if ArKO mice were sexually experienced and pretreated for $\sim 1$ week with a small dose of EB, thus suggesting an interaction between slow genomic and fast nongenomic actions of estrogen. This form of interaction seems to have a general nature: castrated quail had to be pretreated with a small subthreshold dose of testosterone to show a rapid behavioral reaction to a single injection of $\mathrm{E}_{2}$ (Cornil et al., 2006a), and rapid effects of $E_{2}$ were observed in sexually experienced males that had been recently castrated, and their sexual behavior had not completely vanished (Cross and Roselli, 1999). The neural mechanisms underlying the rapid stimulatory effects of $\mathrm{E}_{2}$ on male sexual behavior apparently need to be primed first by steroid hormones.

These additive effects are reminiscent of similar genomic/ nongenomic (or more correctly nuclear/membrane) interactions previously identified in the activation of female rat sexual receptivity (Kow and Pfaff, 2004) and in the induction by $\mathrm{E}_{2}$ of transcriptional activity in a nerve cell line (Vasudevan et al., 2001). In these two cases, however, a two-pulse hormone administration schedule showed that a membrane-initiated action of $\mathrm{E}_{2}$ (mediated by changes in kinase activity) potentiates subsequent transcriptional activity of a second estrogen pulse (cell line) or lordosis activation by estrogen and progesterone. It is therefore possible that in these two types of experiments the kinasemediated membrane action of $E_{2}$ first produced indirect nongenomic effects (through a currently unidentified cascade of intracellular second messengers) that could quite easily synergize with the genomic action of the second $\mathrm{E}_{2}$ pulse.

The interactions described here for the activation of male sex- ual behavior by $\mathrm{E}_{2}$ might involve similar mechanisms (membrane-initiated action coupled to more classical modulations of transcription), but acting in the reverse order (slow presumably genomic action first, followed by rapid presumably nongenomic stimulation). This reverse time sequence makes it quite unlikely that indirect genomic effects could mediate the rapid effects of the single $E_{2}$ injection because behavioral modifications are observed within $10-15 \mathrm{~min}$ of the injection. A direct membrane-initiated change in intracellular signaling is therefore more likely to explain the behavioral effects. The effects of estrogen demonstrated here in male mice are thus more similar to the genomic/nongenomic dual actions of progesterone on female hamster lordosis, which combines a genomic action in the ventromedial nucleus of the hypothalamus with a nongenomic, very rapid action in the mesencephalic ventral tegmental area (DeBold and Frye, 1994; Frye, 2001).

\section{Rapid effect of aromatase inhibition}

We additionally demonstrate here that a single injection of an aromatase inhibitor almost completely suppresses expression of most aspects of male sexual behavior with latencies as short as 10 min after injection, and this effect disappears within $24 \mathrm{~h}$. A broad array of convergent data indicates that this behavioral inhibition is highly specific both from the behavioral and neuroendocrine point of view and does not result from nonspecific detrimental effects of the inhibitor.

At the behavioral level, the rapid inhibitions of mounts and intromissions were not systematically accompanied by a significant decrease in ano-genital olfactory investigations, suggesting that injected mice were still socially and possibly sexually interested in females. In most cases, there was a decrease in the average frequency of AGIs after injection of the aromatase inhibitor, but this decrease was not as systematic as for components of the copulatory sequence and frequently did not reach statistical significance. This part of the behavioral repertoire is thus less (not) affected by the treatment. In addition, no changes in locomotor activity in the open field and no changes in odor preference for an estrous female were detected after treatment with aromatase inhibitors. Therefore, the behavioral effects observed does neither result from a general inhibition of arousal and activity nor from a major decrease in sexual motivation (maintenance of substantial levels of AGI and of olfactory preference for females). The behavioral inhibition specifically concerns the performance component of male sexual behavior, leaving relatively intact the motivational aspects of this behavior.

The behavioral effects of aromatase inhibitors appear also highly specific from the neuroendocrine point of view. First, very similar inhibitions were observed with three different highly specific aromatase inhibitors that are chemically unrelated (VOR is a nonsteroidal inhibitor, ATD and its metabolite 17-OH-ATD are steroids). Second, effects of the inhibitors were fully reversed by a concomitant injection of a large dose of $\mathrm{E}_{2}$. Why a full restoration of behavior could not be accomplished by injection of more physiological doses of $\mathrm{E}_{2}$ presumably relates to the fact that aromatase localized directly at the neuronal, and even at the presynaptic, level produces higher local concentrations of estrogens than observed in the periphery [for additional discussion, see Balthazart and Ball (2006) and Cornil et al. (2006c)]. This notion is supported by the observation that aspects of estrogendependent hippocampal synaptic plasticity, which are inhibited in cultured brain slices by treatment with an aromatase inhibitor, cannot be restored by exposing these slices to concentrations of $E_{2}$ that are typically seen in the plasma of male 
$\left(10^{-12} \mathrm{M}\right)$ or even of female $\left(10^{-10} \mathrm{M}\right)$ rats but can only be restored by concentrations 1000 -fold larger $\left[10^{-7} \mathrm{M}\right.$ (Kretz et al., 2004)]. Estrogens derived from local aromatization of testosterone are thus more effective in stimulating synaptic plasticity (Kretz et al., 2004) or male sexual behavior [present study and Cornil et al. (2006c) for similar data in quail] than peripheral estrogens.

Finally and most importantly, the behavioral effects of aromatase inhibitors were not observed in ArKO males in which sexual behavior had been activated by exogenous EB. This observation formally demonstrates that the behavioral inhibition does not result from a currently nonidentified potentially deleterious effect of the inhibitors but relates directly to the blockade of AA.

\section{Local brain estrogen production and bioavailability modulates expression of male sexual behavior}

Together, the present experiments demonstrate that both upregulation and downregulation of brain estrogen concentrations rapidly affect in parallel the expression of male sexual behavior in ArKO and WT mice. Similar effects, although often slower and smaller in amplitude, were previously observed in rats or quail (Cross and Roselli, 1999; Cornil et al., 2006a,b). The present results thus probably reflect mechanisms of behavior control that broadly apply to vertebrates.

These results, in addition to previous reports demonstrating that brain $\mathrm{E}_{2}$ is produced at the presynaptic level (Schlinger and Callard, 1989; Naftolin et al., 1996; Peterson et al., 2005) in a manner that is rapidly modulated via calcium-dependent phosphorylations (Balthazart et al., 2001, 2003, 2006), support the notions that $\mathrm{E}_{2}$ produced by brain aromatase displays most, if not all, the functional characteristics of neurotransmitters or at least neuromodulators in their "liberalized" version as conceptualized by Snyder and collaborators (Snyder and Ferris, 2000; Baranano et al., 2001) [for further elaboration of this notion, see Balthazart and Ball (2006)].

Transmitter action is usually terminated by enzymatic degradation and/or by reuptake or diffusion in the case of gaseous transmitters such as nitric oxide. The mechanisms that terminate estrogen action within minutes after inhibition of estrogen production have not been identified and will undoubtedly be difficult to establish because these experiments require the assay of $\mathrm{E}_{2}$ concentrations in discrete parts of the CNS, possibly in the synaptic cleft itself, a task that probably cannot be accomplished with current technologies. The demonstration that rapid changes in sexual behavior reflect rapid changes in $E_{2}$ availability may provide, after the site of rapid action of $E_{2}$ has been identified, a new methodological tool to address above-mentioned questions in the absence of suitable assay techniques.

\section{References}

Agarwal VR, Sinton CM, Liang C, Fisher C, German DC, Simpson ER (2000) Upregulation of estrogen receptors in the forebrain of aromatase knockout (ArKO) mice. Mol Cell Endocrinol 162:9-16.

Bakker J, Honda S, Harada N, Balthazart J (2002a) Sexual partner preference requires a functional aromatase (Cyp19) gene in male mice. Horm Behav 42:158-171.

Bakker J, Honda SI, Harada N, Balthazart J (2002b) The aromatase knockout mouse provides new evidence that estradiol is required during development in the female for the expression of sociosexual behaviors in adulthood. J Neurosci 22:9104-9112.

Bakker J, Honda S, Harada N, Balthazart J (2004) Restoration of male sexual behavior by adult exogenous estrogens in male aromatase knockout mice. Horm Behav 46:1-10.
Balthazart J, Ball GF (1998) New insights into the regulation and function of brain estrogen synthase (aromatase). Trends Neurosci 21:243-249.

Balthazart J, Ball GF (2006) Is brain estradiol a hormone or a neurotransmitter? Trends Neurosci 29:241-249.

Balthazart J, Baillien M, Ball GF (2001) Rapid and reversible inhibition of brain aromatase activity. J Neuroendocrinol 13:61-71.

Balthazart J, Baillien M, Charlier TD, Ball GF (2003) Calcium-dependent phosphorylation processes control brain aromatase in quail. Eur J Neurosci 17:1591-1606.

Balthazart J, Baillien M, Ball GF (2006) Rapid control of brain aromatase activity by glutamatergic inputs. Endocrinology 147:359-366.

Baranano DE, Ferris CD, Snyder SH (2001) Atypical neural messengers. Trends Neurosci 24:99-106.

Cornil CA, Seutin V, Motte P, Balthazart J (2004) Electrophysiological and neurochemical characterization of neurons of the medial preoptic area in Japanese quail (Coturnix japonica). Brain Res 1029:224-240.

Cornil CA, Dalla C, Papadopoulu-Daifoti Z, Baillien M, Dejace C, Ball GF, Balthazart J (2005) Rapid decreases in preoptic aromatase activity and brain monoamine concentrations after engaging in male sexual behavior. Endocrinology 146:3809-3820.

Cornil CA, Dalla C, Papadopoulou-Daifoti Z, Baillien M, Balthazart J (2006a) Estradiol rapidly activates male sexual behavior and affects brain monoamine levels in the quail brain. Behav Brain Res 166:110-123.

Cornil CA, Taziaux M, Baillien M, Ball GF, Balthazart J (2006b) Rapid effects of aromatase inhibition on male reproductive behaviors in Japanese quail. Horm Behav 49:45-67.

Cornil CA, Ball GF, Balthazart J (2006c) Functional significance of the rapid regulation of brain estrogen action: where do the estrogens come from? Brain Res 1126:2-26.

Cross E, Roselli CE (1999) 17beta-estradiol rapidly facilitates chemoinvestigation and mounting in castrated male rats. Am J Physiol Regul Integr Comp Physiol 276:R1346-R1350.

DeBold JF, Frye CA (1994) Genomic and non-genomic actions of progesterone in the control of female hamster sexual behavior. Horm Behav 28:445-453.

De Coster R, Wouters W, Bowden CR, Vanden Bossche H, Bruynseels J, Tuman RW, Van Ginckel R, Snoeck E, Van Peer A, Janssen PAJ (1990) New non-steroidal aromatase inhibitors: focus on R76713. J Steroid Biochem 37:335-341.

Dominguez JM, Gil M, Hull EM (2006) Preoptic glutamate facilitates male sexual behavior. J Neurosci 26:1699-1703.

Ellinwood WE, Hess DL, Roselli CE, Spies HG, Resko JA (1984) Inhibition of aromatization stimulates luteinizing hormone and testosterone secretion in adult male rhesus monkeys. J Clin Endocrinol Metab 59:1088-1096.

Frye CA (2001) The role of neurosteroids and nongenomic effects of progestins in the ventral tegmental area in mediating sexual receptivity of rodents. Horm Behav 40:226-233.

Honda S, Harada N, Ito S, Takagi Y, Maeda S (1998) Disruption of sexual behavior in male aromatase-deficient mice lacking exons 1 and 2 of the cyp19 gene. Biochem Biophys Res Commun 252:445-449.

Hull EM, Meisel RL, Sachs BD (2002) Male sexual behavior. In: Hormones, brain and behavior (Pfaff DW, Arnold AP, Etgen AM, Fahrbach SE, Rubin RT, eds), pp 1-137. San Diego: Academic.

Keller M, Douhard D, Baum MJ, Bakker J (2006) Sexual experience does not compensate for the disruptive effects of zinc sulfacte-lesioning of the main olfactory epithelium on sexual behavior in male mice. Chem Senses 31:753-762.

Kelly MJ, Ronnekleiv OK (2002) Rapid membrane effects of estrogen in the central nervous system. In: Hormones, brain and behavior (Pfaff DW, Arnold AP, Etgen AM, Fahrbach SE, Rubin RT, eds), pp 361-380. San Diego: Academic.

Kow L-M, Pfaff DW (2004) The membrane actions of estrogens can potentiate their lordosis behavior-facilitating genomic actions. Proc Natl Acad Sci USA 101:12354-12357.

Kretz O, Fester L, Wehrenberg U, Zhou L, Brauckmann S, Zhao S, PrangeKiel J, Naumann T, Jarry H, Frotscher M, Rune GM (2004) Hippocampal synapses depend on hippocampal estrogen synthesis. J Neurosci 24:5913-5921.

Matsumoto T, Honda S, Harada N (2003) Alteration in sex-specific behaviors in male mice lacking the aromatase gene. Neuroendocrinology 77:416-424. 
McEwen BS, Alves SE (1999) Estrogen actions in the central nervous system. Endocr Rev 20:279-307.

Meisel RL, Sachs BD (1994) The physiology of male sexual behavior. In: The physiology of reproduction, Ed 2, Vol 2 (Knobil E, Neill JD, eds), pp 3-105. New York: Raven.

Naftolin F, Ryan KJ, Davies IJ, Reddy VV, Flores F, Petro Z, Kuhn M, White RJ, Takaoka Y, Wolin L (1975) The formation of estrogens by central neuroendocrine tissues. Rec Prog Horm Res 31:295-319.

Naftolin F, Horvath TL, Jakab RL, Leranth C, Harada N, Balthazart J (1996) Aromatase immunoreactivity in axon terminals of the vertebrate brain—an immunocytochemical study on quail, rat, monkey and human tissues. Neuroendocrinology 63:149-155.

Peterson RS, Yarram L, Schlinger BA, Saldanha CJ (2005) Aromatase is presynaptic and sexually dimorphic in the adult zebra finch brain. Proc Biol Sci 272:2089-2096.

Schlinger BA, Callard GV (1989) Localization of aromatase in synaptosomal and microsomal subfractions of quail (Coturnix coturnix japonica) brain Neuroendocrinology 49:434-441.

Siegel S, Castellan NJ (1988) Nonparametric statistics for the behavioral sciences. Boston: McGraw Hill.

Snyder SH, Ferris CD (2000) Novel neurotransmitters and their neuropsychiatric relevance. Am J Psychiatry 157:1738-1751.

Vasudevan N, Kow L-M, Pfaff DW (2001) Early membrane estrogenic effects required for full expression of slower genomic actions in a nerve cell line. Proc Natl Acad Sci USA 98:12267-12271.

Wersinger SR, Rissman EF (2000) Oestrogen receptor alpha is essential for female-directed chemo-investigatory behaviour but is not required for the pheromone-induced luteinizing hormone surge in male mice. J Neuroendocrinol 12:103-110.

Wesson DW, Keller M, Douhard Q, Baum MJ, Bakker J (2006) Enhanced urinary odor discrimination in female aromatase knockout (ArKO) mice. Horm Behav 49:580-586. 